\title{
Inverse and predictive modeling of seepage into underground openings
}

\author{
S. Finsterle*, C. F. Ahlers, R. C. Trautz, and P. J. Cook
}

Earth Sciences Division, Lawrence Berkeley National Laboratory, University of California, Berkeley, California

\begin{abstract}
We discuss the development and calibration of a model for predicting seepage into underground openings. Seepage is a key factor affecting the performance of the potential nuclear-waste repository at Yucca Mountain, Nevada. Three-dimensional numerical models were developed to simulate field tests in which water was released from boreholes above excavated niches. Data from air-injection tests were geostatistically analyzed to infer the heterogeneous structure of the fracture permeability field. The heterogeneous continuum model was then calibrated against the measured amount of water that seeped into the opening. This approach resulted in the estimation of model-related, seepage-specific parameters on the scale of interest. The ability of the calibrated model to predict seepage was examined by comparing calculated with measured seepage rates from additional experiments conducted in different portions of the fracture network. We conclude that an effective capillary-strength parameter is suitable to characterize seepage-related features and processes for use in a prediction model of average seepage into potential waste emplacement drifts.
\end{abstract}

Keywords: capillary barrier, unsaturated zone, parameter estimation

\footnotetext{
* Corresponding author: Fax: +1-510-486-5686; e-mail: SAFinsterle@lbl.gov
} 


\section{Introduction}

Seepage of water into emplacement drifts for nuclear waste is considered a key factor affecting the long-term safety of a potential repository at Yucca Mountain, Nevada. The number of waste packages contacted by water, the corrosion rate of engineered barriers and waste containers, the dissolution and mobilization of radioactive contaminants, and their release and migration towards the accessible environment all depend on the rate, the chemical composition, and the spatial and temporal distribution of water seeping into the waste-emplacement drifts.

Accurately estimating seepage into underground openings excavated from an unsaturated fractured formation requires process understanding on a wide range of scales. Processes to be studied include (1) the mountain-scale distribution of percolation flux, (2) the intermediate-scale channeling, bifurcation, and dispersion of flow in the fracture network, (3) the small-scale capillary-barrier effect in the boundary layer around the opening, and (4) the micro-scale phenomena of film flow, drop formation, and drop detachment at the drift surface. In addition, the thermodynamic environment in the drift (temperature, relative humidity, ventilation regime, etc.) must be known as it impacts the boundary condition at the drift wall.

Developing a comprehensive, physically based seepage model that covers all scales discussed above would require a large amount of characterization data that are difficult or practically impossible to measure in the field. Moreover, a suite of model assumptions would have to be made to relate fracture and surface properties to hydrogeologic model parameters. Finally, the spatial and temporal resolution of a numerical model necessary to accurately and explicitly capture all the seepage-relevant factors would yield a very large system of coupled equations, which is most likely impractical to solve. 
Because of the complexity inherent in the seepage process, previous analyses were limited to certain aspects of the problem under specific conditions. For example, analytical solutions to the so-called seepage-exclusion problem were developed in a series of papers by Philip and coworkers for a variety of idealized cavity shapes, assuming steady, uniform downward flow in homogeneous, isotropic porous media with an exponential relationship between hydraulic conductivity and water potential (Philip et al., 1989a,b; Philip, 1989a,b, 1990). Several analytical and numerical studies were performed in which capillary-barrier performance in engineered or naturally layered systems was investigated (Frind et al., 1977; Ross, 1990; Oldenburg and Pruess, 1993; Warrick et al., 1997; Webb, 1997). Ho and Webb (1998a) and Birkholzer et al. (1999) examined the impact of heterogeneity on the distribution and rate of water flow across a capillary barrier. Ho (1997) and Or and Ghezzehei (2000) analyzed drop formation and drop detachment as well as evaporation of droplets forming within rough fractures or emerging from fractured formations. These studies provide insight into the seepage mechanism and help identify key parameters affecting seepage.

In order to perform site-specific seepage predictions, we propose to develop a physically based process model using effective parameters that are directly determined from seepage experiments. This approach, outlined below, is limited in that no detailed predictions of drip frequency and seepage location are made. Instead, predicted seepage values are averaged in time and over a drift section of a certain length (in our case the length of a waste package), i.e., they refer to the temporal and spatial scale of interest for a long-term assessment of seepage into waste-emplacement drifts. The scope of this paper is further restricted to studying inflow of liquid water under isothermal conditions, i.e., we are not concerned with vapor diffusion, condensation of water vapor within the drift, or the chemical composition of the dripping water. 
To study drift seepage, a series of air-injection and liquid-release tests were conducted in boreholes drilled above excavated openings. We first describe these experiments and the preliminary processing of the data, before we discuss the development of a numerical model that is calibrated against the observed data to estimate seepage-relevant parameters.

\section{Air-Injection and Seepage Experiments}

\subsection{Objectives}

The overall test objective was to collect data that allow for the determination of effective, seepage-relevant parameters for subsequent use in seepage prediction models. Besides the geometry of the drift, capillarity and permeability are the key factors affecting seepage. Seepage is mainly governed by the capability of individual fractures to hold water by capillary forces, and by the permeability and connectivity of the fracture network, which enables water to be diverted around the drift. Both properties determine the effectiveness of the capillary barrier, which is the process that diverts flow and thus reduces seepage rates below the prevailing percolation flux.

If inversely determined from seepage data alone, permeability and capillarity would be strongly correlated, i.e., they cannot be estimated simultaneously with acceptably low estimation uncertainties. Two different sets of experiments were performed to independently obtain permeability (and its spatial variability) and an appropriate parameter describing the capillary strength of the fracture network. Air-injection tests were aimed at determining permeability (see Section 2.3), whereas liquid-release tests were conducted to infer seepage-relevant capillary strength parameters (see Section 2.4).

\subsection{Test Locations and Borehole Layout}


Drift-scale field tests were initiated in 1997 to investigate potential seepage into underground openings that are similar in shape and size to a waste-emplacement drift (Wang et al., 1999). Short drifts ranging from $6.3 \mathrm{~m}$ to $15.0 \mathrm{~m}$ in length were excavated into the walls of the Exploratory Studies Facility (ESF), a large-diameter tunnel constructed at Yucca Mountain, Nevada. These short excavations are referred to as niches. Boreholes were installed to facilitate characterization of the rock using air-injection tests, and to investigate seepage processes by means of liquid-release tests. We focus here on the results from two niches. The first niche site (hereafter referred to as Niche 3107) consists of a 6.3-m long drift located in an area of relatively low fracture density; the second niche (Niche 4788) is an 8.2-m long drift located in an area exhibiting relatively high fracture density. Prior to niche excavation, boreholes were drilled as shown in Figure 1 to gain access to the rock for testing and monitoring purposes. Three boreholes designated UL, UM, and UR (upper left, upper middle, and upper right, respectively) were installed above each niche parallel to the niche axis, approximately one meter apart.

\subsection{Air-Injection Tests}

Air-injection tests were conducted in several borehole intervals prior to and after niche excavation to determine the permeability distribution of the formation and to study potential permeability changes as a result of stress relief during niche excavation. The tests were performed by isolating one-foot $(0.3 \mathrm{~m})$ sections of the boreholes using an inflatable packer system and then injecting compressed air at a constant rate into the isolated injection interval. The pressure buildup in the injection interval was monitored with time until steady-state conditions were reached, which typically occurred within a few minutes (Wang et al., 1999). Permeability values, $k\left[\mathrm{~m}^{2}\right]$, were derived from the steady-state pressure data based on the following, modified Hvorslev solution for ellipsoidal flow from a finite-length line source (LeCain, 1995): 


$$
k=\frac{P_{s c} Q_{s c} \mu \ln \left(L / r_{w}\right) T_{f}}{\pi L\left(P_{2}^{2}-P_{1}^{2}\right) T_{s c}}
$$

Here, $Q_{s c}\left[\mathrm{~m}^{3} \mathrm{~s}^{-1}\right]$ is the injection rate at standard conditions, $P_{2}[\mathrm{~Pa}]$ is the steady-state pressure in the injection zone, $P_{1}[\mathrm{~Pa}]$ and $T_{f}[\mathrm{~K}]$ are the formation pressure and temperature, $L[\mathrm{~m}]$ and $r_{w}[\mathrm{~m}]$ are the borehole length and radius, and $P_{s c}[\mathrm{~Pa}]$ and $T_{s c}[\mathrm{~K}]$ are standard pressure and temperature, respectively. Assuming that the matrix is much less permeable than the fractures and that the fractures are essentially dry, Eq. (1) can be considered an estimate of the fracture permeability on the scale of the interval length.

The permeability around the niche is likely to be increased as a result of fracture dilatation caused by stress release during niche excavation (Wang and Elsworth, 1999). Since seepage is mainly determined by the formation properties within the boundary layer in the immediate vicinity of the opening, it is reasonable to use post-excavation air-permeability data for seepage calculations. Prior to geostatistical analysis of the data, permeability estimates from borehole intervals located outside of the footprint of the niches were removed from the data set. Statistically, they belong to a separate population of values from an area of relatively undisturbed rock of lower permeability; this area was not directly involved in the seepage process.

The mean and standard deviation of the 78 log-permeability values derived for Niche 3107 are $\log _{10}(k)=-12.13 \pm 0.80$; the corresponding values for Niche 4788 are $-11.79 \pm 0.84$ based on 63 data points. The standard deviations reflect spatial variability at the location. The logpermeability data were geostatistically analyzed to provide a basis for generating spatially correlated permeability fields. Empirical semivariograms were evaluated for each niche. The parameters determined by fitting a spherical semivariogram model to the data indicate weak 
spatial correlation. For Niche 3107, a relatively short correlation length of $0.6 \mathrm{~m}$ was obtained. For Niche 4788, a correlation length of $1.3 \mathrm{~m}$ was estimated. However, the determined nugget effect of 0.29 is close to the sill value of 0.55 , again implying that correlation is weak. These geostatistical properties were preserved during the generation of heterogeneous permeability fields (see Figure 2 below).

\subsection{Liquid-Release Tests}

Multiple liquid-release tests were performed to characterize seepage into an underground opening. The tests were performed by sealing a short section of the borehole above the opening using an inflatable packer system and then releasing water at a constant rate into the isolated test interval. Any water that migrated from the borehole to the ceiling and dripped into the opening was captured and weighed, yielding the cumulative seepage as a function of time.

In each test event, between 5 and 25 liters of water were injected over a period ranging from 1 day to 24 days, using different injection rates (ranging from $0.5 \mathrm{~mL} / \mathrm{min}$ to $5.5 \mathrm{~mL} / \mathrm{min}$ ) with different lengths of inactivity between individual test events. No detectable overpressures were created in the packed-off intervals, i.e., the injection flux was likely below the volume-averaged saturated hydraulic conductivity.

From the 22 tests conducted, only 15 lead to seepage into the niche. The injection rates used in the remaining tests were relatively low so that all of the water was either diverted around the opening (i.e., the induced percolation flux was below the seepage threshold), or it evaporated (i.e., the potential seepage rate was lower than the evaporation rate). Also note that a certain amount of water was stored in the initially dry fractures and had imbibed into the matrix. 
The tests in which no seepage occurred cannot be used for calibration, because the corresponding inverse problem would be ill posed. These events (along with experiments showing seepage) will be used for testing the predictive capabilities of the calibrated model (see Section 3.4).

\section{Model Calibration and Seepage Prediction}

\subsection{Model Development}

As discussed in the introduction, we are concerned with the effective seepage behavior on the scale of a drift segment rather than with individual seepage events from specific dripping locations. Given this objective as well as the lack of small-scale characterization data and appropriate constitutive relations that could constrain the model, unsaturated flow through the densely fractured formation and seepage into the niche is represented by a simplified, heterogeneous continuum model. The appropriateness of using the continuum approach for simulating discrete flow and seepage under the specific conditions of this study has been examined by Finsterle (2000). It was demonstrated that predictions of average seepage behavior made with an appropriately calibrated continuum model are consistent with seepage data generated using a discrete feature model.

The matrix is not explicitly represented in this single-continuum model because its contributions to flow and seepage are expected to be small. This does not imply that matrix effects as well as the impact of microfractures are neglected. They are accounted for through the estimation of effective parameters, as will be discussed below.

For each niche, a three-dimensional primary mesh is generated with $\mathrm{X}-\mathrm{Y}-\mathrm{Z}$ dimensions of $6.5 \mathrm{~m} \times 1.5 \mathrm{~m} \times 5.0 \mathrm{~m}$ for Niche 3107 , and $6.0 \mathrm{~m} \times 2.0 \mathrm{~m} \times 5.0 \mathrm{~m}$ for Niche 4788 , discretized 
into regular gridblocks with side lengths of $0.1 \mathrm{~m} \times 0.1 \mathrm{~m} \times 0.1 \mathrm{~m}$. An opening with the surveyed geometry of the niche is cut from the mesh, preserving the large-amplitude ceiling roughness. A very small nodal distance is defined between the interfaces representing the drift surface and the gridblocks denoting the drift, which sets boundary conditions directly at the drift wall. The length of the last vertical connection from the gridblocks representing the formation and the interface denoting the drift surface is thus $\Delta \mathrm{Z} / 2=0.05 \mathrm{~m}$. The impact of this discretization scheme on predicted seepage and thus on the estimated parameters will be discussed in Section 4 .

The meshes shown in Figure 2 contain approximately 35,000 gridblocks and 100,000 connections between them. The spherical semivariogram models along with the cumulative distribution functions inferred from the air-injection tests are used to generate three-dimensional, spatially correlated permeability fields based on sequential indicator simulation (Deutsch and Journel, 1992). The fields are conditioned on the measured air-permeability data and mapped onto the numerical grid (see Figure 2). Only one permeability field realization is produced for each niche.

On the scale of an individual gridblock, we assume that unsaturated flow can be described using Richards' equation (Richards, 1931), which is implemented in the integral finite-difference simulator TOUGH2 (Pruess et al., 1999):

$$
\frac{\partial}{\partial t} \phi S \rho=\operatorname{div}\left[k \frac{k_{r}}{\mu} \rho \nabla(P+\rho g z)\right]
$$

Here, $t[\mathrm{~s}]$ is time, $\phi$ is porosity, $S$ is liquid saturation, $\rho\left[\mathrm{kg} \mathrm{m}^{-3}\right]$ is liquid density, $k\left[\mathrm{~m}^{2}\right]$ is absolute permeability, $k_{r}$ is relative permeability, $\mu[\mathrm{Pa} \mathrm{s}]$ is viscosity, $g\left[\mathrm{~m} \mathrm{~s}^{-2}\right]$ is gravitational 
acceleration, $z[\mathrm{~m}]$ is the vertical coordinate (positive upward), and $P=P_{r e f}+P_{c}[\mathrm{~Pa}]$ is liquidphase pressure, where $P_{r e f}[\mathrm{~Pa}]$ is a reference gas pressure and $P_{c}[\mathrm{~Pa}]$ is capillary pressure. Relative permeability and capillary pressure are functions of liquid saturation as given by van Genuchten (1980):

$$
\begin{gathered}
k_{r}=S_{e}^{1 / 2}\left[1-\left(1-S_{e}^{1 / m}\right)^{m}\right]^{2} \\
P_{c}=-\frac{1}{\alpha}\left[S_{e}^{-1 / m}-1\right]^{1-m}
\end{gathered}
$$

where the effective saturation $S_{e}$ is defined as

$$
S_{e}=\frac{S-S_{l r}}{1-S_{l r}}
$$

In the van Genuchten model, $S_{l r}$ is residual liquid saturation, and $\alpha\left[\mathrm{Pa}^{-1}\right]$ and $m$ are fitting parameters. The use of continuous relative-permeability and capillary-pressure functions, which apply to porous media, is considered appropriate also for small fracture segments that are roughwalled and/or partially filled with porous material.

Table 1 summarizes the hydrogeologic properties as well as the boundary conditions. Most property values are taken from a parameter set that was derived from laboratory experiments performed on core samples as well as through calibration against saturation, water potential, and pneumatic pressure data using a large-scale model of Yucca Mountain (Bandurraga and Bodvarsson, 1999; Ahlers et al., 1999). The parameter set is considered representative of the middle nonlithophysal zone of the Topopah Spring welded tuff under base-case infiltration conditions. Reference permeability is taken from the analysis of air-injection tests conducted in boreholes above each niche. Porosity $\phi$ and the van Genuchten capillary-strength parameter $1 / \alpha$ will both be estimated through inverse modeling. 
The following boundary and initial conditions are specified. The reference pressure in the drift is kept constant at one bar without a capillary suction (i.e., it is assumed that the air in the drift is at $100 \%$ relative humidity). Water is allowed to enter, but prevented from exiting the drift. Thus, the temporal change of water in the drift element represents the cumulative seepage collected in a capture system installed in the drift. The background percolation flux at the experimental site is extracted from the UZ site-scale model (Wu et al., 1999) and applied uniformly as a constant flux across the top model boundary. The fluxes of $2.54 \mathrm{~mm} / \mathrm{yr}$ for Niche 3107 and $2.02 \mathrm{~mm} / \mathrm{yr}$ for Niche 4788 are significantly lower than the injection flux applied during the liquid-release tests, and thus are not expected to greatly affect the simulation results. A free-drainage boundary condition is specified at the bottom of the model to prevent the development of an unphysical capillary end effect. No-flow boundary conditions are imposed at the left, right, back, and front sides of the model. The model is then run to steady state, providing the initial saturation distribution for all subsequent simulations.

\subsection{Parameter and Data Selection}

The inverse modeling approach followed here is based on the classical minimization of the weighted least-squares objective function:

$$
S=\mathbf{r}^{T} \mathbf{C}_{z z}^{-1} \mathbf{r}
$$

where the residual vector $\mathbf{r}$ contains the differences between the measured seepage rate, $z^{*}$, and the corresponding model prediction, $z(\mathbf{p})$, which is a function of the unknown, $n$ dimensional parameter vector $\mathbf{p}$, i.e., $r_{i}=\left(z_{i}^{*}-z(\mathbf{p})_{i}\right), i=1 \ldots m$, where $m$ is the number of calibration points. The inverse of the covariance matrix $\mathbf{C}_{z z}$, which holds the expected variances of the final residuals on its diagonal, is used as a weighting matrix. The objective function is 
minimized using the Levenberg-Marquardt algorithm, which requires calculating the $m \times n$ Jacobian matrix $\mathbf{J}$, holding the partial derivatives of the predicted seepage with respect to the unknown parameters, $J_{i j}=\partial z_{i} / \partial p_{j}$.

We first discuss the choice of the parameters to be subjected to the estimation process, and then proceed to the selection of the data and their uncertainty. It is obvious that only the most sensitive parameters can be estimated, which in our case are the capillary-strength parameter $1 / \alpha$, absolute permeability $k$, and effective porosity $\phi$. Sensitivity, while a necessary requirement, is not sufficient for successful parameter estimation. Since the simulated seepage can be increased by decreasing capillary strength, porosity, or permeability, all parameter pairs are strongly negatively correlated if inversely determined from seepage data alone. Consequently, it is unlikely that they can be determined independently from one another and with a reasonably low estimation uncertainty. To weaken the correlations and to reduce the ill-posedness of the inverse problem, only two of the three parameters are estimated, namely the porosity and the capillarystrength parameter; the reference permeability is fixed at the value independently estimated from the air-injection tests described in Section 2.3. Since the capillary strength parameter tends to vary over a large range and is likely log-normally distributed, we choose to estimate its logarithm instead of its value. The effective fracture porosity is expected to be small, close to its physical lower bound of zero, which also suggests estimating its logarithm.

Next, appropriate seepage data are selected for calibration and model confirmation. As mentioned earlier, it is a key element of our approach to use seepage data on the appropriate scale to ensure that the relevant processes are captured and embedded into an effective parameter. Estimating effective parameters partly compensates for processes and features that are not explicitly considered in the model. For example, if drift wall roughness, film flow, flow 
diversion through microfractures, and other unmodeled processes affect seepage, the observed seepage rate is increased or decreased accordingly, and the estimated parameters are adjusted such that they automatically reflect these impacts. Because the combined effect of unmodeled processes is lumped into an effective parameter, it is important to realize that the estimated parameters are not generally applicable: they are process- and scale-specific as well as modelrelated, and can only be considered optimal for a prediction model whose structure is consistent with that of the calibration model.

Instantaneous seepage rates are used instead of the measured cumulative seepage data because an error in the prediction of the early-time seepage behavior leads to a shift in the cumulative seepage curve. Such a shift would induce a bias in the estimated parameters, even if only late-time data were used in the inversion. In general, early-time seepage data are relatively strongly affected by storage effects. Moreover, they reflect the properties of only a few fractures that connect the injection interval with the point at the drift surface where seepage is initiated. These fractures may not be representative of the drift-scale properties of the fracture network engaged in the seepage process under near-steady-state conditions. Moreover, these few fractures are likely to be conceptually different from the larger-scale network providing connectivity for flow diversion around the drift. Consequently, matching early-time data potentially leads to an unwanted bias in the estimated parameters. Late-time, near-steady seepage rate data are less impacted by storage effects, allowing for a more representative estimation.

For each of the two niches, data from multiple seepage tests performed in a given borehole interval are jointly inverted. Only two borehole intervals were tested in Niche 3107, one in Borehole UL and one in UM. However, the tests conducted in Borehole UL are not useable for calibration, because no seepage was initiated, i.e., the inverse problem would be ill-posed. (Note 
that a well-posed inverse problem could be formulated if these data were jointly inverted with non-zero seepage rates from other test intervals). Nevertheless, the no-seepage test results can be used for model confirmation purposes (see Section 3.4 below). Of the nine tests performed in the interval 4.88-5.18 of Borehole UM, three are selected for model calibration because of their variety in injection rates $(0.9,2.4$, and $5.4 \mathrm{~mL} / \mathrm{min})$ and different seepage behavior (from zero seepage to substantial seepage). The remaining tests in this borehole are reserved for model confirmation.

Three intervals were tested in Niche 4788, all leading to seepage. In each interval, the lowand medium-rate tests that resulted in seepage were selected for model calibration. The highestrate and lowest-rate seepage tests are reserved for model confirmation to determine whether the porosity and $1 / \alpha$ estimates can be successfully applied to conditions that are outside the calibration range. In summary, nine liquid-release experiments-each providing transient seepage rate data - were analyzed in four separate inversions, yielding four parameter sets, each representing a different portion of the fracture network and different section of the drift ceiling.

\subsection{Model Calibration}

The TOUGH2 models developed to simulate the seepage experiments are automatically calibrated using the Levenberg-Marquardt algorithm implemented in the iTOUGH2 code (Finsterle, 1999). Different initial values for the two parameters $1 / \alpha$ and $\phi$ are provided for each inversion to make sure that the initial simulation results in non-zero seepage rates and thus nonzero sensitivity coefficients, which is a requirement for a derivative-based minimization algorithm. 
As an example, Figure 3 shows the late-time saturation distribution for three simulated seepage tests conducted in Boreholes UL, UM, and UR of Niche 4788, indicating that the injected water is partly diverted around the niche as a result of the capillary barrier effect.

Figures 4 and 5 show a comparison between the measured seepage rates and those obtained with the calibrated models of Niche 3107 and Niche 4788, respectively. The calibrated models match the data reasonably well considering that multiple test events performed with different injection rates were inverted simultaneously using a simplified continuum model (note the different scales on the Y-axes). The seepage rate data of the tests conducted in Niche 3107 on 4-27-99 and Niche 4788 on 12-10-99 were considered less reliable, and a smaller weight was assigned to these data for the inversion. As a result, the model slightly overpredicts these data, whereas the other jointly inverted test events were — on average—well matched.

The resulting estimates of $\log (1 / \alpha)$ and $\log (\phi)$ are shown in Table 2 . Note that while the $\log (1 / \alpha)$ estimates are closely grouped for all four locations, the estimate of $\log (\phi)$ for Niche 3107 differs from those obtained for Niche 4788. Also note that the estimate of $\log (1 / \alpha)$ for Niche 3107 is the highest. These differences seem reasonable considering the observed permeability in each of the niches. Because Niche 3107 has a lower permeability and a lower observed fracture frequency, it is expected to have a lower $\phi$ and a higher $1 / \alpha$.

A similar analysis of short-term liquid-release tests yielded substantially lower estimates of $\log (1 / \alpha)$ (Finsterle and Trautz, 2001). The discrepancy is a result of two factors. First, in the earlier modeling study, the connection between the formation and drift element was implemented in a way that inhibits seepage to a certain extent compared to the current study. This effect was compensated during the inversion by a reduction in the capillary-strength parameter. This underscores the importance of recognizing that the estimated parameters refer to the specific 
model structure. Secondly, the very small amount of water used in those earlier experiments (approximately 1 liter was released) may have lead to a substantial bias in the estimate of $\log (1 / \alpha)$ if storage effects are not accurately captured by the model. This potential problem has been largely eliminated in the current study by performing long-term seepage experiments.

\subsection{Model Confirmation}

Models are often developed — and most useful - to infer behavior that cannot be observed directly (such as long-term, near-steady seepage under natural, low percolation fluxes). However, a model can only be calibrated and tested against data that can be observed (such as seepage data from transient liquid-release tests involving a finite amount of water). A model confirmation exercise against independent, observable data is a necessary step for confidence building. Nevertheless, an extrapolation of the model beyond its tested grounds remains inherently dangerous, as discussed by Oreskes et al. (1994).

Blind predictions of seepage rates are performed with the calibrated model, simulating tests that were not used for model calibration. These tests engaged a different portion of the fracture system and a different drift section, and involved injection and seepage rates both above and below those used for calibration. If seepage rates are successfully predicted (according to an acceptance criterion discussed below), confidence is gained that the seepage process is adequately conceptualized.

A probabilistic acceptance criterion is adopted to ensure that prediction uncertainty is included in the model confirmation process as well as in future model predictions. Seepage rate predictions are considered successful if at least $95 \%$ of the observed late-time data lie within the $95 \%$ simulation uncertainty band calculated by the calibrated model, or if the seepage rates are 
overpredicted by the model (deemed conservative). This means that the seepage rates calculated with the best-estimate parameter set are expected to match the data with reasonable accuracy, where "reasonable" is defined by the prediction uncertainty. The uncertainty in the input parameters is propagated through the model to arrive at prediction uncertainties. First-ordersecond-moment (FOSM) analysis is used to examine the prediction uncertainty:

$$
\mathbf{C}_{y y}=\mathbf{J} \mathbf{C}_{p p} \mathbf{J}^{T}
$$

Here, $\mathbf{C}_{p p}$ and $\mathbf{C}_{y y}$ are the covariance matrices of the input parameters and the model prediction, respectively, and $\mathbf{J}$ is the sensitivity matrix relating the input to the output. FOSM is applicable only if the model behaves approximately linearly about the mean within the range defined by $\mathbf{C}_{p p}$.

The appropriateness of the mean parameter for the middle nonlithophysal zone (see Table 2, Columns 5 and 8) is determined by using it to predict seepage rate data from all tests conducted in this unit. In addition to uncertainty in the $\log (1 / \alpha)$ and $\log (\phi)$ estimates, uncertainty in the reference permeability $\log (k)$ is also included, because variability among test locations was not accounted for in the calibrations, which were based on fixed, location-specific permeabilities. The standard error of the mean permeability was determined from all available air-permeability data.

Basing model confirmation on averaged values is considered appropriate given the intended use of the seepage model and its parameters. Also notice that meeting the acceptance criterion with a mean parameter set is more difficult than with sets that are tailored to the specific conditions at a given location.

Figure 6 shows the observed seepage rate data, the predicted seepage rates, and the 95\% simulation uncertainty bands for six representative examples out of the 22 liquid-release tests 
analyzed for model confirmation. The model prediction is considered successful if either of the following criteria is met: (1) late-time seepage rates are well reproduced (a poor prediction of early-time seepage data is considered acceptable, because the intended use of the model does not include the accurate simulation of short-term transient seepage events); (2) the model overpredicts the observed seepage rates; overpredicting seepage is conservative and deemed acceptable; (3) the model underpredicts the observed seepage rates but at least $95 \%$ of the data lie within the simulation uncertainty calculated by FOSM. Note that the FOSM linearity requirement breaks down for experiments near or below the seepage threshold. If no seepage is predicted with the mean parameter set, the uncertainty band vanishes. Furthermore, FOSM may predict negative seepage rates, an artifact of the approach that is of no concern because it only affects the lower bound of the predicted seepage rates.

Based on these criteria, 19 out of the 22 tests are considered acceptable. In two of the three remaining tests, the observed late-time seepage rates are slightly larger than the relatively narrow uncertainty band. The tests would be considered acceptable if the chosen uncertainty in the input parameters were slightly increased, or if nonlinearities were included in the uncertainty propagation analysis. The only prediction that clearly fails the acceptance criteria is the simulation of a liquid-release test conducted on 1-5-00 in Borehole UR of Niche 4788. Note that seepage data from a higher-rate experiment and a lower-rate experiment conducted in the same interval were both well predicted.

\section{Discussion}

The calibration and confirmation exercises described in Section 3 demonstrate that seepage into underground openings excavated from a highly fractured formation can be predicted using a 
heterogeneous continuum model, provided that the model is calibrated against seepage-relevant data. This last requirement is crucial, because the parameters employed in such a model must be effective parameters related to the specific process and its simplifications in the model. Using calibrated parameters can be considered the main advantage of the approach, or an unacceptable limitation. It is recognized that many processes affecting seepage cannot be described deterministically, mainly because of a lack of characterization data. However, their phenomenological effect is evidently captured in the observed seepage data, and is therefore automatically included in the estimated parameter.

Combining many of these effects into a lumped parameter requires some justification. For example, drift-wall roughness leads to increased seepage, which is accounted for by a reduction of $1 / \alpha$ by a pressure head that approximately corresponds to the amplitude of the undulation. (Note that the actual perturbation of $1 / \alpha$ depends on the geometrical details of the roughness with respect to the orientation of the fracture system and the drift.) Because the physical impact of surface roughness on seepage (Ho and Webb, 1998b; Hughson and Dodge, 2000) is indeed related to the capillary rise needed to divert flow out of a topographic low, capturing this effect in an equivalent $1 / \alpha$ value is appropriate.

Similarly, discrete fracture segments intersected by the opening increase seepage beyond the value expected from a porous formation. During the inversion, however, the $1 / \alpha$ value is appropriately reduced to account for this effect. Note that numerical discretization has an impact similar to that of discrete fracture segments intersected by the drift. In summary, the resulting $1 / \alpha$ estimate (1) relates to the specific role of capillarity as part of the seepage process, (2) includes the average length of the final fracture segments intersected by the opening (an effect similar to surface roughness), and (3) is tailored to the details of the numerical implementation. 
The parameter must be considered process-specific and model-related, which explains why the estimate may deviate from that inferred from data probing a different process and analyzed using a different conceptual model.

Accepting the limited applicability of the parameters derived by inverse modeling, there is no stringent need for an excessively fine grid resolution at the drift boundary. However, it is crucial that a similar model structure be used for the prediction model, consistent with that used during calibration. If this last condition is fulfilled, the estimated parameters can be considered optimal for the specific problem at hand.

As a final point of discussion, we examine the potential impact of evaporation on the observed seepage data and thus on the estimated parameters. If evaporation were significant during the course of the liquid-release tests, the estimated parameters reflect these conditions and can therefore only be used for the prediction of seepage into a drift under comparable relative humidity conditions. In our model, it is assumed that evaporation losses during the seepage experiments are negligible, an assumption considered reasonable, because both niche sites discussed in this paper were sealed off during the seepage experiments, and a humidifier was placed in Niche 4788 to further reduce the evaporation potential. However, uncertainties in evaporation rate estimates are directly translated into uncertainty in the overall mass balance, which states that the sum of water (1) seeping into the opening, (2) being diverted around the opening, (3) being stored in the formation, and (4) evaporating and escaping in the vapor phase must be equal to the amount of water injected. The current model takes processes (1) through (3) into account (either explicitly or through the estimation of effective parameters), but makes the assumption that (4) is small and can be neglected. If evaporation rates are a significant fraction of the difference between the injection rate and the observed seepage rate, the resulting estimates 
are biased. Since both $1 / \alpha$ and $\phi$ are overestimated, the predicted seepage rate into a drift with near $100 \%$ relative humidity will be underestimated.

The actual evaporation during test conditions is difficult to measure or estimate. Ho (1997) and Or and Ghezzehei (2000) provide a detailed description of evaporation mechanisms on the scale of individual water droplets within fractures or emerging from fractured formations. The evapo-infiltration amounts calculated by Ho (1997) are significantly lower than the applied injection rates, suggesting a very minor influence of evaporation on measured seepage rates in experiments conducted in the niches. However, evaporation from a large surface of free or nearly free water-either at the drift wall or in the capture system — may be significant. As injected water reaches the opening, it spreads along the surface on account of capillarity within the rough drift wall. As a result, water potentially seeping into the opening may not only form droplets with a small surface area, but may be spread over a large area, providing a large surface for evaporation. Depending on the evaporation potential of the air in the opening, the water film covering the wall of the opening may evaporate at a rate comparable to the injection or seepage rates. Moreover, evaporation may be significant during periods of active ventilation with high airflows in the drift in combination with low injection rates. Under these specific conditions, the evaporation rate may exceed the potential seepage rate, preventing the development of liquid droplets that drip into the opening.

The evaporation issue can be addressed either experimentally or numerically. If monitored, the evaporation process can be included in a model that accounts for fully coupled heat and moisture exchange between the unsaturated formation and the atmosphere in the open drift. The seepage model is currently revised to include evaporation effects. The additional parameters required for this extended model can be determined through simple evaporation experiments. 


\section{Summary and Conclusions}

The complexity of the hydrogeologic system and the seepage process itself calls for a modeling approach that is feasible and tailored to the specific study objectives. It is recognized that (1) detailed simulation of individual seeps is not necessary to estimate average seepage rates into waste-emplacement drifts, (2) certain factors affecting seepage can be lumped into an effective parameter, (3) calibrating a model against data from seepage experiments ensures the model captures the relevant processes, (4) estimating effective parameters partly compensates for processes and features that are not explicitly considered in the model, (5) the estimated parameters are optimal and can be directly used in the prediction model, and (6) despite its simplicity, the proposed continuum model is sufficiently complex to reproduce the observed data and is thus a viable candidate to perform seepage predictions; its relative parsimony is considered an advantage.

Three-dimensional continuum models were developed, representing niche locations in the middle nonlithophysal zone of the Topopah Spring tuff at Yucca Mountain, Nevada. The models were developed based on limited information; specifically, no fracture mapping data were used because the mapped geometric characteristics and hydraulic properties are not necessarily related to each other. Air-injection data were analyzed to provide the basis for generating heterogeneous, spatially correlated permeability fields. Seepage rate data from multiple liquid-release tests were jointly inverted to estimate seepage-specific, model-related parameters on the scale of interest. Specifically, an effective capillary-strength parameter $1 / \alpha$ was determined. The ability of the fractures to hold part of the percolating water and to divert it out of local topographic lows, along intersected fracture segments, and eventually around the drift is the key property defining the 
effectiveness of the capillary barrier. Other seepage-relevant processes such as film flow and surface roughness also depend on the capillarity, and it is therefore considered suitable to lump them into the $1 / \alpha$ parameter.

In addition, an effective porosity value was determined. The estimate mostly reflects fracture porosity, which is the pore space engaged in the transport of water from the release point to the seepage location and around the drift. However, it also includes additional components that contributed to the storage effect seen during the experiment, such as micro fractures and matrix imbibition, which are not accounted for explicitly in this single-continuum model.

The successful calibration of seepage rate data and the fact that sensible parameter values were obtained confirms that the underlying conceptual model is appropriate. More importantly, the successful prediction of most of the seepage tests gives confidence that the calibrated model is able to predict seepage under similar conditions, covering a range of percolation fluxes consistent with those expected in a high-infiltration scenario in combination with substantial flow focusing. Additional seepage studies using fully coupled models of unsaturated fracture flow and in-drift moisture movement will provide the basis for seepage predictions for a wider range of conditions.

Acknowledgment. Thanks are due to M. L. Wilson, C. Doughty, B. Faybishenko, and F. Dodge for their critical comments and valuable suggestions for improvement. This work was supported by the Director, Office of Civilian Radioactive Waste Management, U.S. Department of Energy, through Memorandum Purchase Order EA9013MC5X between Bechtel SAIC Company, LLC and the Ernest Orlando Lawrence Berkeley National Laboratory (Berkeley Lab). The support is 
provided to Berkeley Lab through the U.S. Department of Energy Contract No. DE-AC0376 SF00098. 


\section{References}

Ahlers, C.F., Finsterle, S., and Bodvarsson, G.S., 1999. Characterization and prediction of subsurface pneumatic response at Yucca Mountain, Nevada. J. Contam. Hydrol., 38(1-3): $47-68$.

Bandurraga, T.M. and Bodvarsson, G.S., 1999. Calibrating hydrogeologic parameters for the 3-D site-scale unsaturated zone model of Yucca Mountain, Nevada. J. Contam. Hydrol., 38(1-3): 25-46.

Birkholzer, J., Li, G., Tsang, C.-F., and Tsang, Y., 1999. Modeling studies and analysis of seepage into drifts at Yucca Mountain. J. Contam. Hydrol., 38(1-3): 349-384.

Deutsch, C.V. and Journel, A.G., 1992. GSLIB — Geostatistical Software Library and User's Guide. Oxford University Press, New York.

Finsterle, S., 1999. iTOUGH2 user's guide. Report LBNL-40040. Lawrence Berkeley National Laboratory, Berkeley, California.

Finsterle, S., 2000. Using the continuum approach to model unsaturated flow in fractured rock. Water Resour. Res., 36(8): 2055-2066.

Finsterle, S., and R.C. Trautz, 2001. Numerical modeling of seepage into underground openings, Mining Engineering, 53(9), 52-56, 2001.

Frind, E.O., Gillham, R.W., and Pickens, J.F., 1977. Application of unsaturated flow properties in the design of geologic environments for radioactive waste storage facilities. In: W.G. Gray, G.F. Pinder, and C.A. Brebbia (Editors), Finite Elements in Water Resources. Pentech, London, pp. 3.133-3.163,

Ho, C.K., 1997. Evaporation of pendant water droplets in fractures. Water Resour. Res., 33(12): $2665-2671$. 
Ho, C.K. and Webb, S.W., 1998a. Capillary barrier performance in heterogeneous porous media. Water Resour. Res., 34(4): 603-609.

Ho, C.K. and Webb, S.W., 1998b. The effects of heterogeneity and wavy interfaces on capillary barrier performance. In: K. Pruess (Editor), Proceedings of the TOUGH Workshop '98. Report LBNL-41995, Lawrence Berkeley National Laboratory, Berkeley, California.

Hughson, D.L. and Dodge, F.T., 2000. The effect of cavity wall irregularities on seepage exclusion from horizontal cylindrical underground openings. J. Hydrol., 228: 206-214.

LeCain, G.D., 1995. Pneumatic testing in 45-degree-inclined boreholes in ash-flow tuff near Superior, Arizona. U. S. Geol. Surv. Water-Resour. Invest. Rep. 95-4073, Denver, Colorado.

Leverett, M.C., 1941. Capillary behavior in porous solids. Trans. Soc. Pet. Eng. AIME, 142: $152-169$.

Oldenburg, C.M. and Pruess, K., 1993. On numerical modeling of capillary barriers. Water Resour. Res., 29(4): 1045-1056.

Or, D. and Ghezzehei, T.A., 2000. Dripping into subterranean cavities from unsaturated fractures under evaporative conditions. Water Resour. Res., 36(2): 381-393.

Oreskes, N., Shrader-Frechette, K., and Belitz, K., 1994. Verification, validation, and confirmation of numerical models in the earth sciences. Science, 264: 641-646.

Philip, J.R., 1989a. The seepage exclusion problem for sloping cylindrical cavities. Water Resour. Res., 25(6): 1447-1448.

Philip, J.R., 1989b. Asymptotic solutions for the seepage exclusion problem for ellipticcylindrical, spheroidal, and strip- and disc-shaped cavities. Water Resour. Res., 25(7): 15311540. 
Philip, J.R., 1990. Some general results on the seepage exclusion problem. Water Resour. Res., 26(3): 369-377.

Philip, J.R., Knight, J.H., and Waechter, R.T., 1989a. Unsaturated seepage and subterranean holes: conspectus, and exclusion problem for cylindrical cavities. Water Resour. Res., 25(1): $16-28$.

Philip, J.R., Knight, J.H., and Waechter, R.T., 1989b. The seepage problems for parabolic and paraboloidal cavities. Water Resour. Res., 25(4): 605-618.

Pruess, K., Oldenburg, C., and Moridis, G., 1999. TOUGH2 user's guide, version 2.0. Report LBNL-43134, Lawrence Berkeley National Laboratory, Berkeley, California.

Richards, L.H., 1931. Capillary conduction of liquids through porous mediums. Physics, 1: $318-333$.

Ross, B., 1990. The diversion capacity of capillary barriers. Water Resour. Res., 27(10): 26252629.

van Genuchten, M.T., 1980. A closed-form equation for predicting the hydraulic conductivity of unsaturated soils. Soil Sci. Soc. Am. J., 44: 892-898.

Wang, J.S.Y. and Elsworth, D., 1999. Permeability changes induced by excavation in fractured tuff. Proceedings of the 37th U.S. Rock Mechanics Symposium, Rock Mechanics for Industry, 2, The American Rock Mechanics Association, Alexandria, Virginia, pp. 751-757.

Wang, J.S.Y., Trautz, R.C., Cook, P.J., Finsterle, S., James, A.L., and Birkholzer, J., 1999. Field tests and model analyses of seepage into drift. J. Contam. Hydrol., 38(1-3): 323-347.

Warrick, A.W., Wierenga, P.J., and Pan, L., 1997. Downward water flow through sloping layers in the vadose zone: analytical solutions for diversions. J. Hydrol., 192: 321-337. 
Webb, S.W., 1997. Generalization of Ross' tilted capillary barrier diversion formula for different two-phase characteristic curves. Water Resour. Res., 33(8): 1855-1859.

Wu, Y.-S., Haukwa, C., and Bodvarsson, G.S., 1999. A site-scale model for fluid and heat flow in the unsaturated zone of Yucca Mountain, Nevada. J. Contam. Hydrol., 38(1-3): 185-215. 
Table 1. Hydrogeologic parameter set and boundary conditions

\begin{tabular}{|c|c|c|c|}
\hline Parameter & Niche 3107 & Niche 4788 & Comment \\
\hline \multicolumn{4}{|c|}{ Hydrogeologic Properties } \\
\hline Permeability $k\left[\mathrm{~m}^{2}\right]$ & $7.31 \times 10^{-13}$ & $1.61 \times 10^{-12}$ & $\begin{array}{l}\text { Inferred from local air- } \\
\text { injection test data }\end{array}$ \\
\hline $\begin{array}{l}\text { Semivariogram } \\
\text { Nugget }\left[\log \left(\mathrm{m}^{2}\right)^{2}\right] \\
\text { Correlation length }[\mathrm{m}] \\
\text { Sill }\left[\log \left(\mathrm{m}^{2}\right)^{2}\right]\end{array}$ & $\begin{array}{l}0.01 \\
0.61 \\
0.49\end{array}$ & $\begin{array}{l}0.29 \\
1.31 \\
0.55 \\
\end{array}$ & $\begin{array}{l}\text { Parameters of spherical } \\
\text { semivariogram model } \\
\text { derived from local air- } \\
\text { permeability data }\end{array}$ \\
\hline van Genuchten $m$ & 0.608 & 0.608 & Ahlers et al. (1999) \\
\hline van Genuchten $n$ & 2.55 & 2.55 & $n=1 /(1-m)$ \\
\hline Residual saturation $S_{l r}$ & 0.01 & 0.01 & Assumed \\
\hline van Genuchten $1 / \alpha[\mathrm{Pa}]$ & $(740)$ & $(550)$ & (To be estimated) \\
\hline Porosity $\phi[\%]$ & $(0.1)$ & $(1.3)$ & (To be estimated) \\
\hline \multicolumn{4}{|c|}{ Boundary Conditions } \\
\hline Drift pressure $[\mathrm{Pa}]$ & $1.0 \times 10^{5}$ & $1.0 \times 10^{5}$ & Constant \\
\hline Percolation flux $[\mathrm{mm} / \mathrm{yr}]$ & 2.54 & 2.02 & From site-scale model \\
\hline
\end{tabular}

Table 2. Estimates of seepage-relevant parameters for each borehole and averaged for the middle nonlithophysal zone of the Topopah Spring unit.

\begin{tabular}{|c|c|c|c|c|c|c|c|}
\hline \multirow[t]{2}{*}{ Niche } & \multirow{2}{*}{$\begin{array}{l}\text { Borehole } \\
\text { Interval }\end{array}$} & \multicolumn{2}{|c|}{ Capillarity Estimate } & \multirow{2}{*}{$\begin{array}{c}\text { Mean } \log (1 / \alpha) \\
\pm \text { Std. Dev. }\end{array}$} & \multicolumn{2}{|c|}{ Porosity Estimate } & \multirow{2}{*}{$\begin{array}{l}\text { Mean } \log (\phi) \\
\pm \text { Std. Dev. }\end{array}$} \\
\hline & & $\log (1 / \alpha)$ & $\begin{array}{l}1 / \alpha \\
{[\mathrm{Pa}]}\end{array}$ & & $\log (\phi)$ & $\phi[\%]$ & \\
\hline 3107 & UM 4.88-5.18 & 2.87 & 741 & \multirow{4}{*}{$\begin{array}{c}2.77 \pm 0.10 \\
(468-741 \mathrm{~Pa})\end{array}$} & -3.00 & 0.1 & \multirow{4}{*}{$\begin{array}{c}-2.17 \pm 0.29 \\
(0.3-1.3 \%)\end{array}$} \\
\hline \multirow[t]{3}{*}{4788} & UL 7.62-7.93 & 2.81 & 646 & & -1.75 & 1.8 & \\
\hline & UM 6.10-6.40 & 2.78 & 603 & & -1.78 & 1.7 & \\
\hline & UR 5.18-5.48 & 2.63 & 427 & & -2.15 & 0.7 & \\
\hline
\end{tabular}




\section{Figure Captions}

Figure 1. Schematic of niche with borehole cluster. Boreholes designated UL, UM, and UR were used for seepage testing. The shape of the niche ceiling is approximate; the roughness of the ceiling is shown in Figure 2.

Figure 2. Computational meshes and permeability field used for calibration of seepage data from (a) Niche 3107, and (b) Niche 4788, shown from an angle below horizontal to display the ceiling roughness incorporated into the mesh.

Figure 3. Late-time saturation distributions for simulated liquid-release tests in Borehole (a) UL, (b) UM, and (c) UR of Niche 4788, showing partial flow diversion around the niche as a result of the capillary barrier effect.

Figure 4. Comparison between simulated and measured seepage rates from Niche 3107.

Figure 5. Comparison between simulated and measured seepage rates from Niche 4788 .

Figure 6. Comparison between predicted (solid line) and measured (symbols) seepage rates. The 95\% uncertainty band (dotted lines) was estimated using First-Order-SecondMoment error propagation analysis. The panels in the top row show examples of predictions that meet the acceptance criteria. The first panel in the center row underpredicts early-time seepage; the second panel overpredicts late-time seepage; both predictions are considered acceptable. The bottom row shows the failed prediction in Borehole UR; the test was conducted at a medium injection rate; the predictions for a low-rate (last panel) and high-rate (not shown) injection from the same interval are acceptable. 


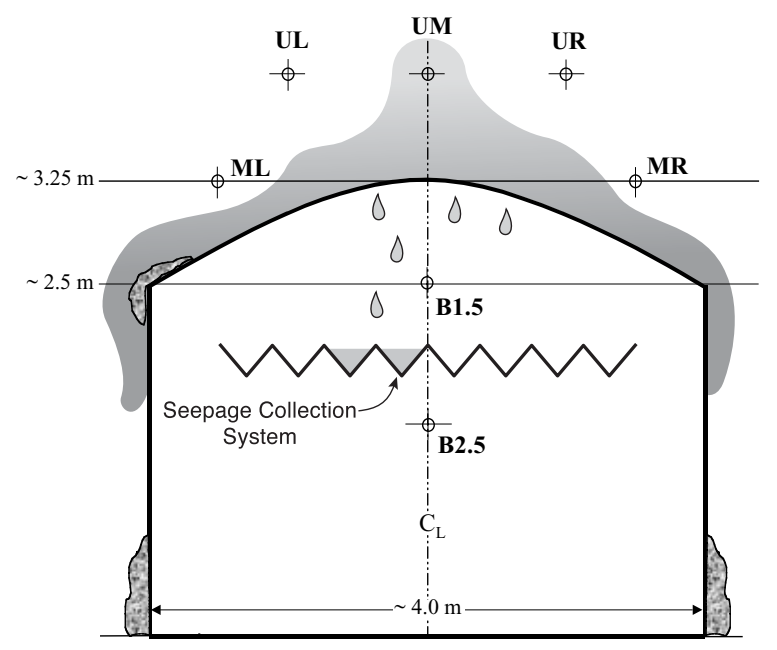

Figure 1. Schematic of niche with borehole cluster. Boreholes designated UL, UM, and UR were used for seepage testing. The shape of the niche ceiling is approximate; the roughness of the ceiling is shown in Figure 2. 


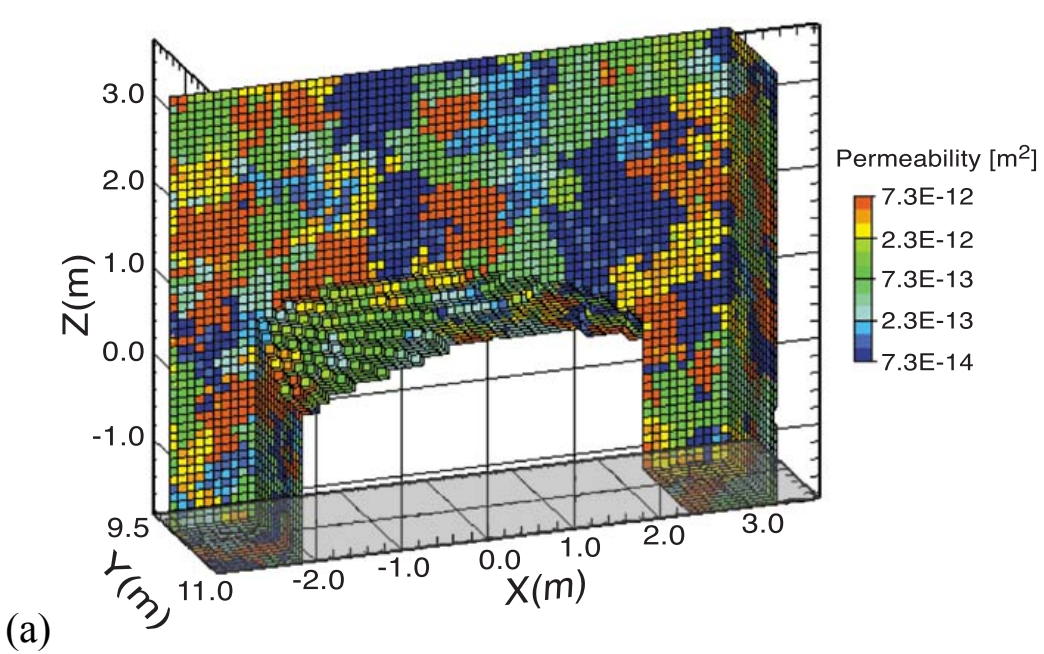

(a)

(b)

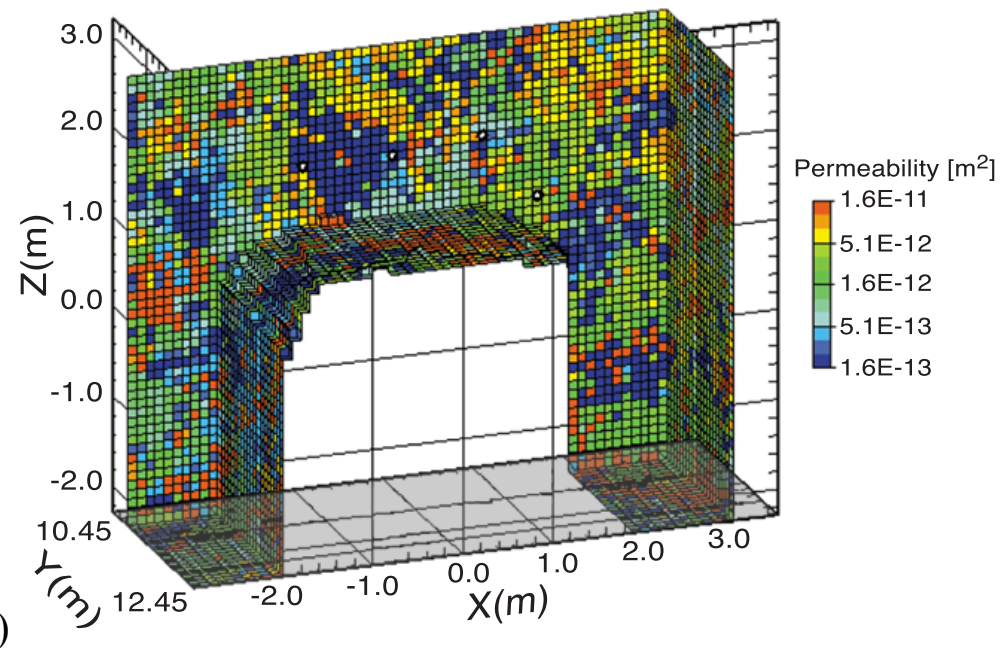

Figure 2. Computational meshes and permeability field used for calibration of seepage data from (a) Niche 3107, and (b) Niche 4788, shown from an angle below horizontal to display the ceiling roughness incorporated into the mesh. 


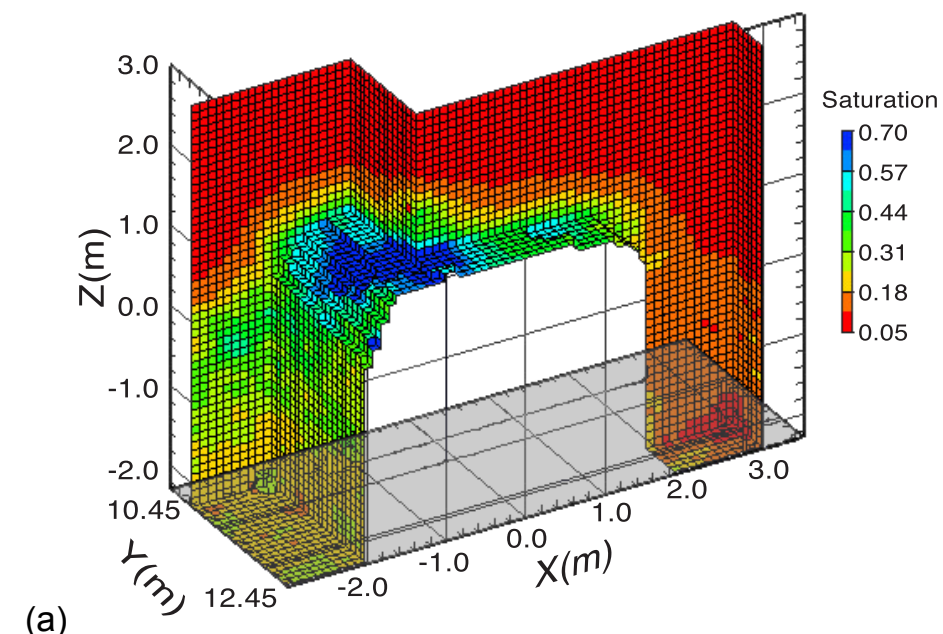

(b)

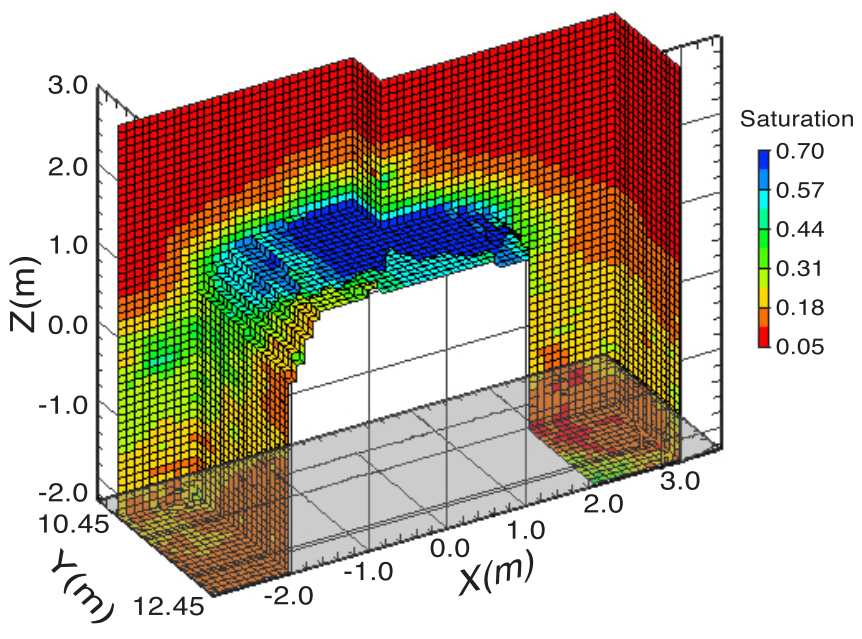

(c)

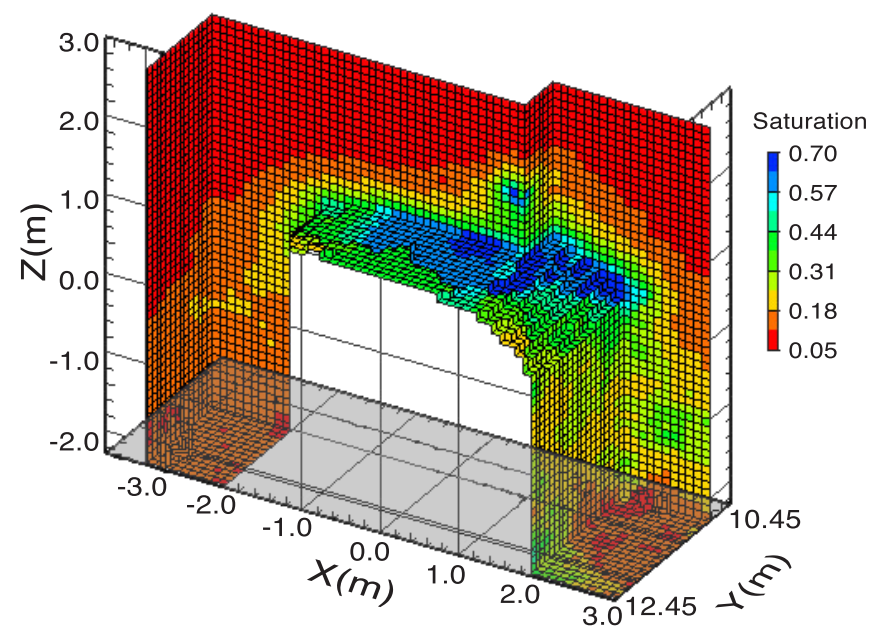

Figure 3. Late-time saturation distributions for simulated liquid-release tests in Borehole (a) UL, (b) UM, and (c) UR of Niche 4788, showing partial flow diversion around the niche as a result of the capillary barrier effect. 

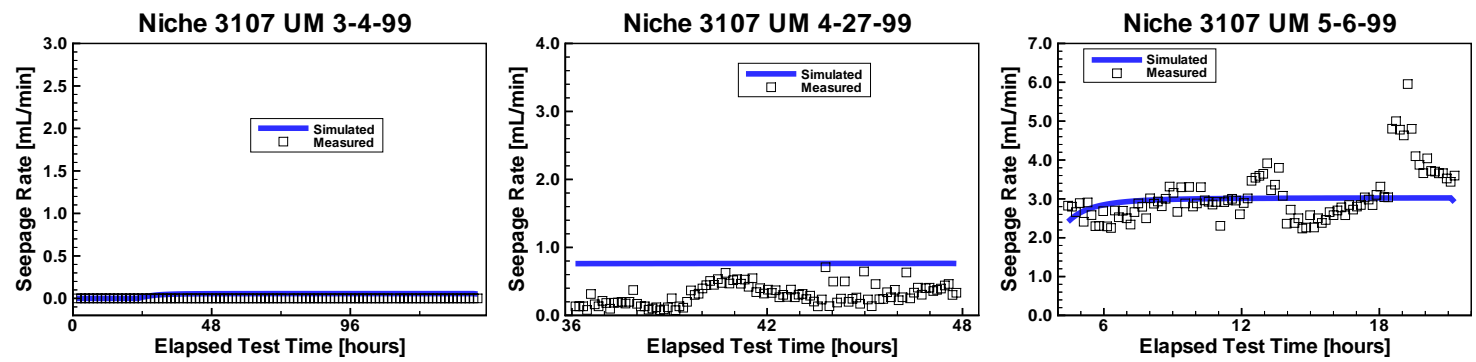

Figure 4. Comparison between simulated and measured seepage rates from Niche 3107 .
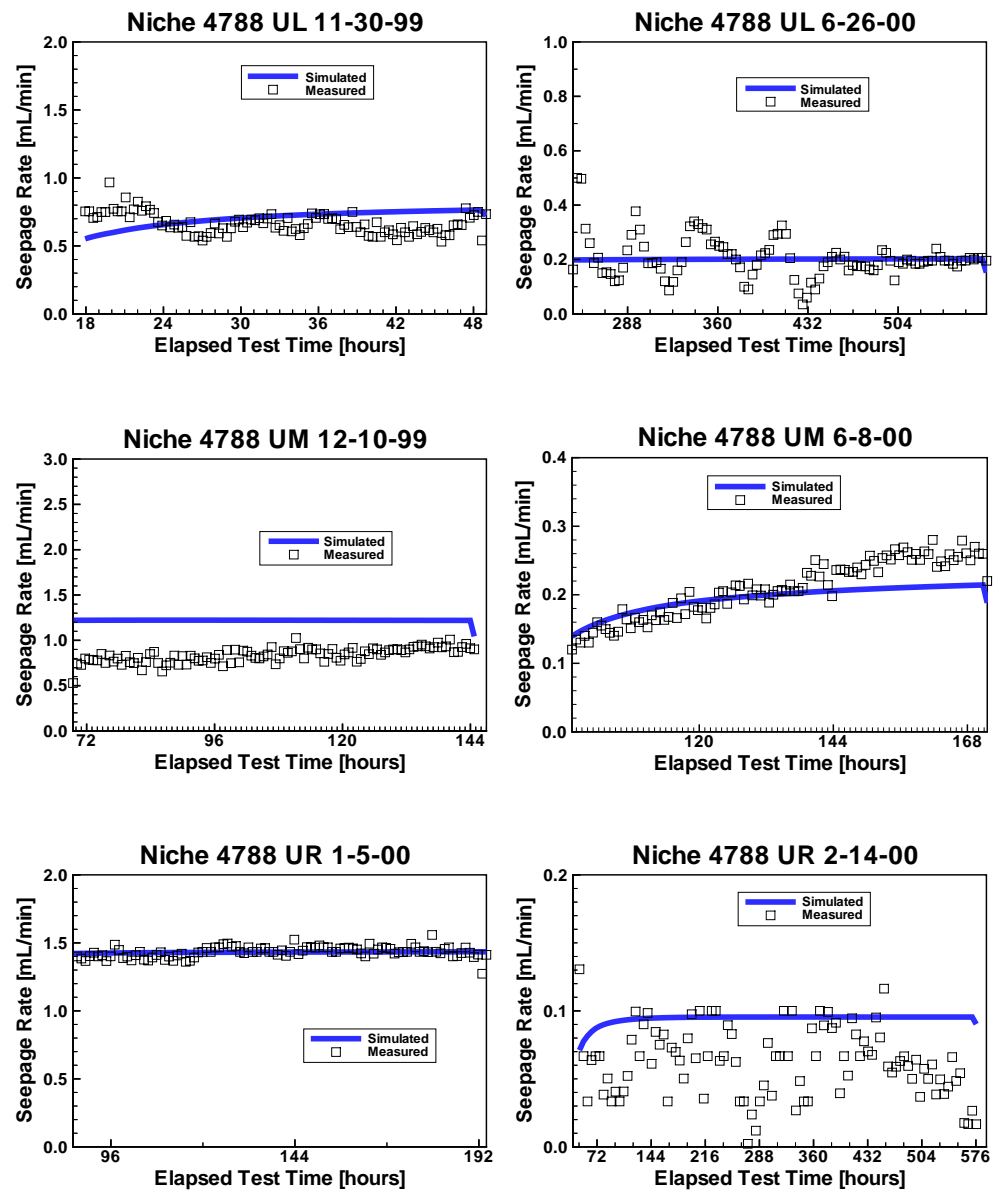

Figure 5. Comparison between simulated and measured seepage rates from Niche 4788 . 

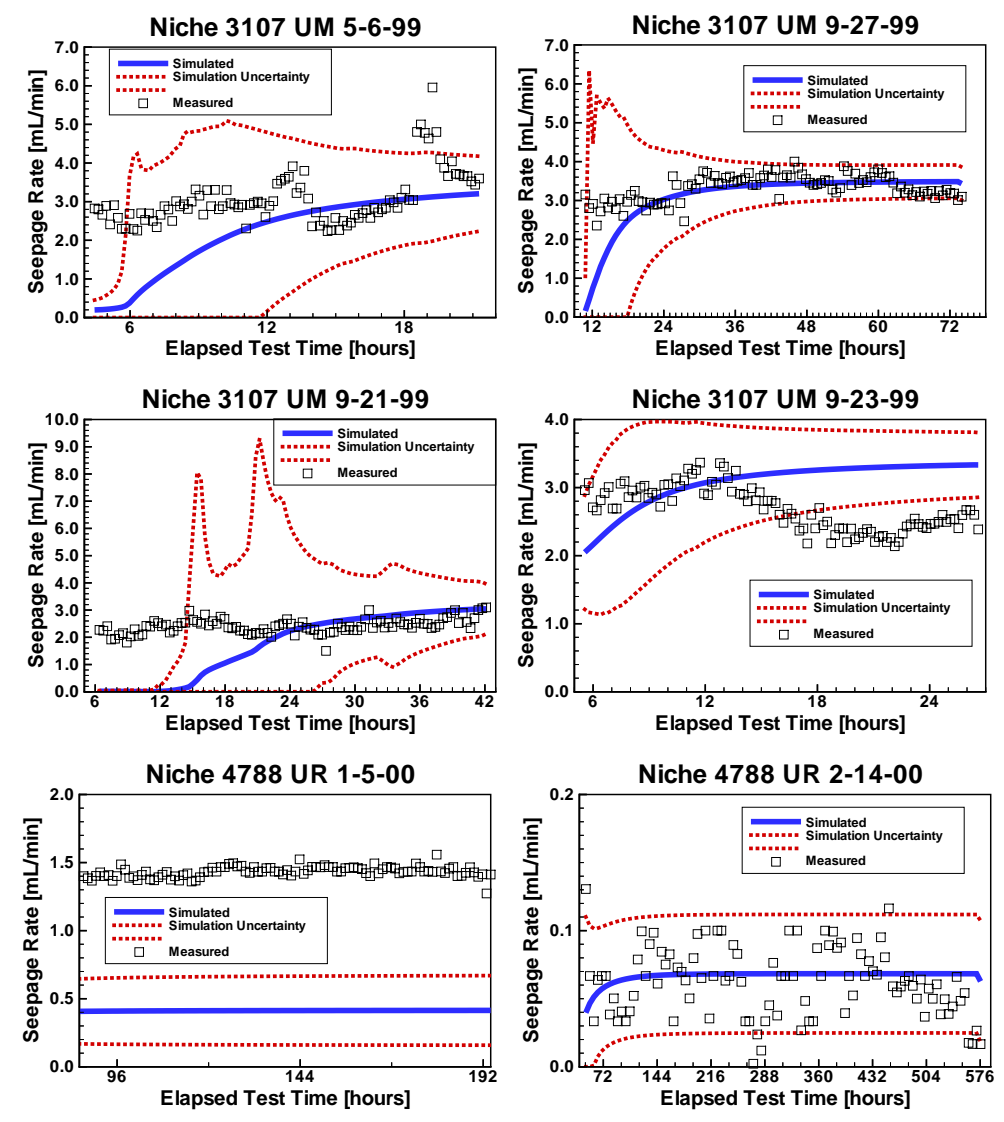

Figure 6. Comparison between predicted (solid line) and measured (symbols) seepage rates. The 95\% uncertainty band (dotted lines) was estimated using First-Order-SecondMoment error propagation analysis. The panels in the top row show examples of predictions that meet the acceptance criteria. The first panel in the center row underpredicts early-time seepage; the second panel overpredicts late-time seepage; both predictions are considered acceptable. The bottom row shows the failed prediction in Borehole UR; the test was conducted at a medium injection rate; the predictions for a low-rate (last panel) and high-rate (not shown) injection from the same interval are acceptable. 